\title{
River bank erosion opposite to transverse groynes
}

\author{
Alessandra Crosato $^{1,2}$, José Bonilla-Porras ${ }^{1}$, Arthur Pinkse ${ }^{2}$, and Tsegaye Yirga Tiga ${ }^{1}$ \\ ${ }^{1}$ IHE Delft, Dept. of water Science and Engineering, Delft, the Netherlands \\ ${ }^{2}$ Delft University of Technology, Fac. of Civil Engineering and Geosciences, Delft, the Netherlands
}

\begin{abstract}
Long series of groynes are built from both river sides to narrow river channels and prevent bank erosion with the aim to improve the conditions for inland navigation and prevent lateral channel migration. Single groynes or short series of groynes are built to impede local bank erosion, deviate the water flow, free an intake or fix the position of migrating bars at certain locations. These structures divert the flow towards the opposite river side where channel bed erosion increases the risk of bank failure. Flow and river bed adaptation have been extensively studied, especially for long series of groynes. Instead, studies dealing with opposite bank erosion caused by single or short series of groynes are still lacking. We investigated this phenomenon in the laboratory and using 2D numerical models with LES. This paper shows some preliminary results.
\end{abstract}

\section{Introduction}

Field observations indicate that single groynes produce extensive opposite bank erosion and that the point of maximum bank retreat is not located opposite to the groyne, but more downstream (Figure 1). Predicting location, length and extent of bank retreat would allow identifying where bank protection is needed. However, investigations considering the effects of groynes on opposite bank erosion are still lacking.

Recent morphodynamic studies show that the flow alteration produced by a groyne results in the formation of a large sediment deposit downstream of the structure (forced bar). Considering straight channels with fixed banks, Duró et al. [1] found that the length of the groyne perpendicular to the flow affects both location and amplitude of this forced bar: longer groynes produce higher bars located at a smaller distance than shorter groynes. Moreover, if the river system is morphodynamically unstable with respect to bar formation, the groyne triggers also the formation of periodic bars more downstream. Since bars affect bank erosion, it is believed that the study of the effects of single groynes on opposite bank erosion should also include downstream bar formation.

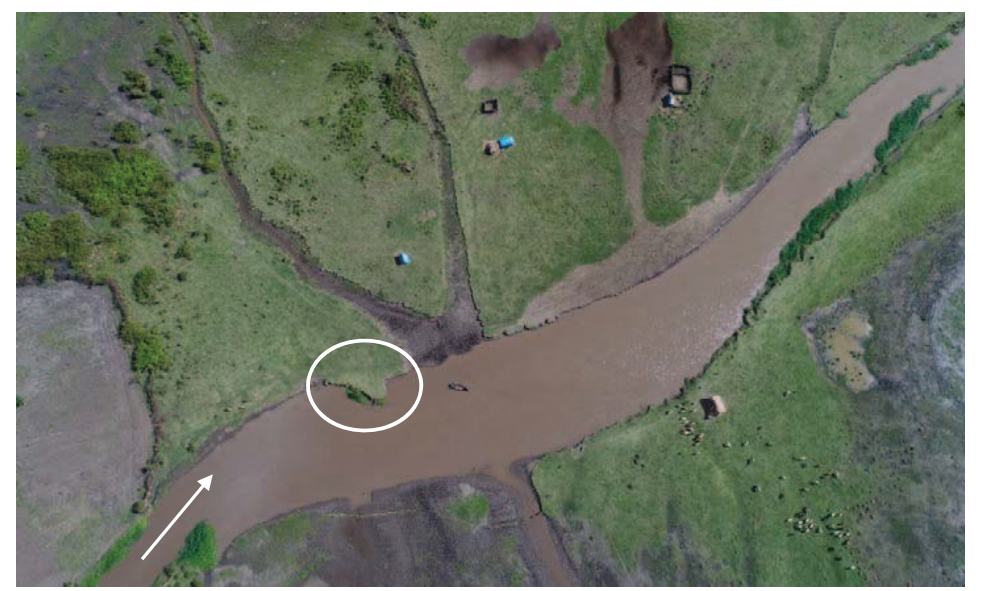

Fig. 1. Lower course of the Mara River (Tanzania). The rock outcrop protruding from the left bank, in the white circle, acts as an isolated groyne and produces opposite bank erosion (visible bank failures). Flow from left to right. UAV image, courtesy of Francesco Bregoli. 
The flow around groynes has been studied extensively in the laboratory (e.g. $[2,3,4])$, as well as numerically (e.g. [5, $6,7])$. Past investigations dealing with the morphological changes caused by groynes focused on the channel bed, in most cases analysing the formation of a scour hole near the groyne tip, and generally considered long series groynes. The results of these studies indicate that the the scour hole geometry depends on Froude number, water depth, ratio of contracted flow width to channel width, angle of inclination and length of the groyne [8 and 9].

To study the pattern of opposite bank retreat caused by single groynes, we analysed the evolution of a straight channel excavated in a sand-bed flume, in which a plate was placed transversally to the flow from the right bank. We considered two groyne lengths and four distinct cases, characterized by different constant flows but identical sediment input rates.

Yossef and Klaassen [10] described the flow characteristics in the vicinity of an isolated groyne and highlighted some important aspects that might be relevant for opposite bank erosion: first, the geometry of the separation region occurring downstream of the groyne; second, the formation of horizontal large eddies that shed from the tip of the groyne; third, the water surface fluctuations related to the migration of the horizontal eddies. Yossef and Klaassen [10] identified the necessity of modelling the flow field with Large Eddy Simulation (LES) in order to better represent the flow pattern. Also the tests carried out by Koken and Constantinescu [6] show that LES is necessary to observe different kinds of vortices occurring in the proximity of the groyne, as well as for the estimation of sediment entrainment regions. Considering this, we complemented our laboratory experiments with numerical modelling. We simulated the depth-averaged flow field (2D) with horizontal LES in upscaled versions of some key experimental tests. Upscaling was meant to: 1) show what type of river is represented by the performed flume experiments and 2) prevent small-scale issues in the hydraulic model (the water depth in the experiments ranged between less than one centimetre to $4 \mathrm{~cm}$ ). Only some preliminary results of the exploratory part of the study are presented here.

\section{Materials and methods}

\subsection{Laboratory experiments}

We carried out a total of 10 experimental tests in the Laboratory of Fluid Mechanics of the Delft University of Technology. The experimental facility consisted of a $7.0 \times 1.2 \times 0.23$ m wooden flume. In a sand layer of $0.18 \mathrm{~m}$, a rectangular channel of $0.25 \times 0.04 \mathrm{~m}$, with horizontal bed, was excavated at the start of each test. The sediment was selected based on its quality to produce banks with some resistance against erosion (poorly sorted sand with $\mathrm{D}_{10}=0.27 \mathrm{~mm}, \mathrm{D}_{50}=1.0 \mathrm{~mm}$, $\mathrm{D}_{90}=1.48 \mathrm{~mm}$ with a density of $2600 \mathrm{~kg} / \mathrm{m}^{3}$ ). A pump recirculated water and four laser beams recorded the bed topography at different times during the experiment. Sediment input from the upstream boundary was the same for all tests: $33.3 \mathrm{~g} /$ minute. Above the flume, a camera took pictures every ten minutes to describe the evolution of the channel. At the end of each test, the camera was also used to follow the drift of small floating objects that were thrown in the water at intervals of a few seconds to allow drawing the stream lines and define local flow velocity vectors. Four discharges were tested $(0.50,0.58,0.67$ and $0.81 \mathrm{1} / \mathrm{s})$, resulting in initial sub-critical flow (Froude numbers between 0.4 and 0.6 ). A groyne perpendicular to the flow narrowed the channel by either $20 \%$ or $50 \%$. Considering the exploratory character of the study, the somehow unrealistic high level of obstruction created by the groyne was meant to produce clear visible effects on the opposite bank. We monitored the evolution of bank alignment and bed topography until a state of morphodynamic equilibrium was reached.

\subsection{Numerical modelling}

The hydrodynamic numerical models were built using the open-source Delft3D software (www.deltares.nl) allowing for Large Eddy Simulation. Because the experiments were carried out in a very small flume and the numerical code might not perform well for small size flows, the systems were upscaled to the size of real rivers. We applied the scaling rules of Froude and Shields, keeping the same value of the roughness coefficient and of the ratios "2D flow adaptation length" $\left(\lambda_{W}\right)$ to channel width, $B$ [11] and "2D water depth adaptation length" $\left(\lambda_{S}\right)$ to channel width [11]. These ratios govern the $2 \mathrm{D}$ behaviour of flow and morphology, with:

$$
\begin{gathered}
\lambda_{W}=\frac{C^{2} h}{2 g} \\
\lambda_{S}=\frac{h}{(m \pi)^{2}}\left(\frac{B}{h}\right)^{2} f(\theta)
\end{gathered}
$$

in which $C=$ Chézy's roughness coefficient $\left(\mathrm{m}^{1 / 2} / \mathrm{s}\right), h=$ water depth $(\mathrm{m}), g=$ acceleration due to gravity $\left(\mathrm{m} / \mathrm{s}^{2}\right), B$ channel with (m), $f(\theta)=$ function of Shields number $(-): f(\theta)=1.7 \sqrt{\theta}$ [12], and $m=$ bar mode (-), a parameter that is used to represent the river bar regime, with $m=1$ corresponding to alternate bars, $m=2$ to central bars and $m>2$ to multiple bars. If $m=>0$, no bars are (theoretically) present in the river channel (stable bed). 
The bar mode can be computed as [13]:

$$
m=\frac{B}{C \pi h} \sqrt{(b-3) f(\theta) g}
$$

with $b=$ exponent of sediment transport rate per unit width as a function of flow velocity [13]. In a generic sediment transport capacity formula the sediment transport rate per unit of channel width, $q_{s}\left(\mathrm{~m}^{2} / \mathrm{s}\right)$, can be expressed as a function of flow velocity, $u(\mathrm{~m} / \mathrm{s})$ :

$$
q_{s}=M u^{b}
$$

in which $M=$ coefficient and $b=$ exponent. The value of $b$ generally falls between 3 and 10. Applying the Engelund and Hansen transport formula [14], valid for sand-bed rivers, results in $b=5$. Values of $b$ above 10 can be found at conditions that are close to initiation of motion, when the sediment transport reacts strongly to changes in flow velocity, which can be often observed in gravel-bed rivers [13].

The upscaled numerical channels were about 220 times larger than the experimental streams, every case having a slightly different upscale ratio. Reynolds numbers had the order of magnitude of a few thousand in the flume experiments, but were about 20 times larger in the corresponding numerical channels. Nevertheless, in all cases the flow could be considered turbulent.

Upscaling allowed us to establish the type of rivers that we were dealing with. Having the same Shields numbers and ratios $\lambda_{S} / B$ as in the experiments, the upscaled numerical channels were found to reproduce rivers with a bed of cobbles having diameters of $10-20 \mathrm{~cm}$. This poses some limitations in the generality of our investigation, since it represents rivers that are typically found in mountain areas, as for instance the upper Arc River (France) [15]. However, this was to be expected, considering the conditions close to initiation of motion that we observed in the experiments and knowing that laboratory streams with a sand bed normally represent gravel-bed rivers (e.g. [16]). To represent sand-bed rivers instead, laboratory flumes should have sediment with smaller density. In any case, the hydrodynamic simulations were not affected by this, because they do not include sediment transport processes. The effects of bed sediment size were only incorporated in the bed roughness coefficient, which had the same value as in the laboratory experiments $\left(C=38 \mathrm{~m}^{1 / 2} / \mathrm{s}\right)$.

The models were calibrated on measured water levels and flow velocity. Model results were then downscaled to be compared to the experimental data. Numerical modelling focused on 6 cases, for each one the model simulated the flow at the initial and final conditions, which differed in longitudinal slope, undisturbed width and bed topography.

\section{Preliminary results}

Poorly graded sand having median diameter of $1 \mathrm{~mm}$ produced vertical banks that retreated through sequences of failures. Bank erosion resulted in channel width adaptation all along the channel. As a result of sediment feeding plus some extra sediment input coming from the eroding banks, the longitudinal slope of the channel gradually increased (Figure 2). All tests were stopped after the slope had reached a final stable configuration, i.e. after 16 hours.

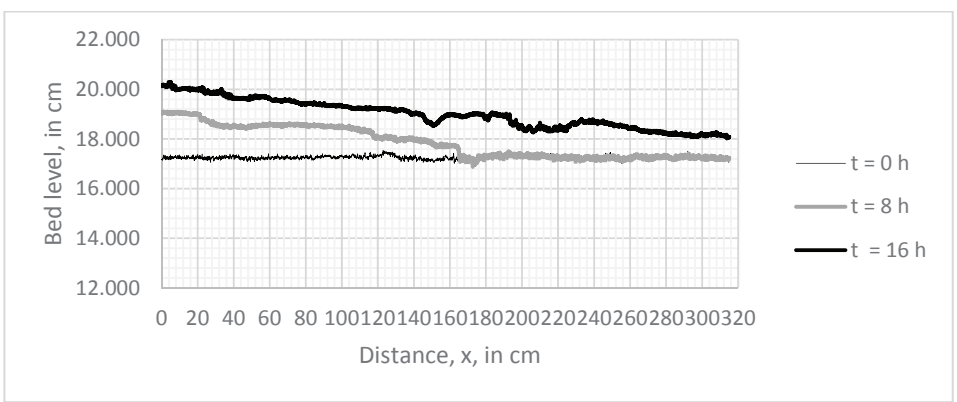

Fig. 2. Example of slope adaptation to sediment inputs. 
As expected, enhanced bank erosion occurred at the side opposite to the groyne. In the final channel configuration, the shape of bank alignment appeared related to the formation of a large bar downstream of the structure (Figure 3 ). With the minimum discharge of $0.5 \mathrm{l} / \mathrm{s}$, the maximum bank retreat rates occurred at a distance from the narrowed cross-section of about 2.5 times the channel width (Figure 3). Our experiments confirm the findings by Duró et al. [1], since shorter groynes produced bars with smaller vertical amplitude, located more downstream.
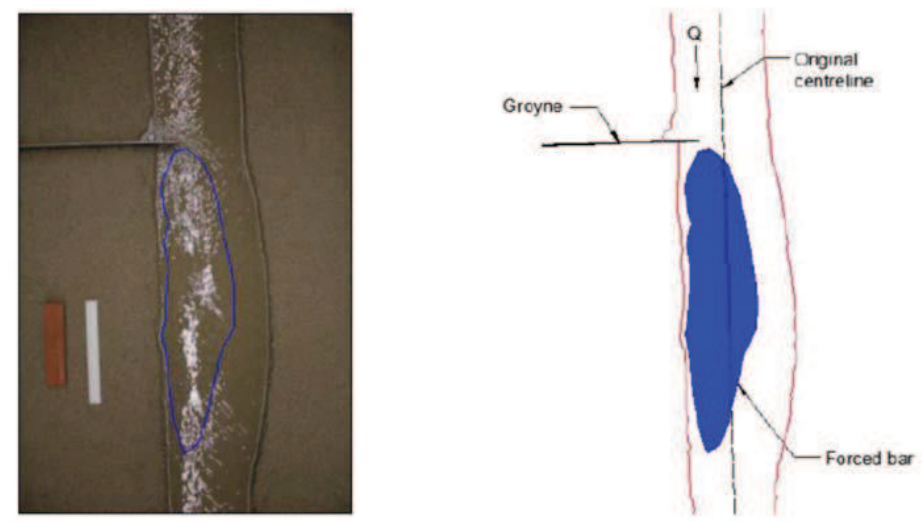

Fig. 3. Bar formation downstream of a groyne obstructing $20 \%$ of the initial channel width and bank alignment at the end of the experiment (final configuration at a discharge $0.50 \mathrm{l} / \mathrm{s}$ ).

Figure 4 shows the final velocity field (after 16 hours) for the discharge of $0.58 \mathrm{l} / \mathrm{s}$ and $50 \%$ groyne obstruction. The highest values of near-bank velocity occurred at a certain distance from the narrowed cross-section, close to the location of maximum bank retreat, at a distance of about 3 times the channel width.

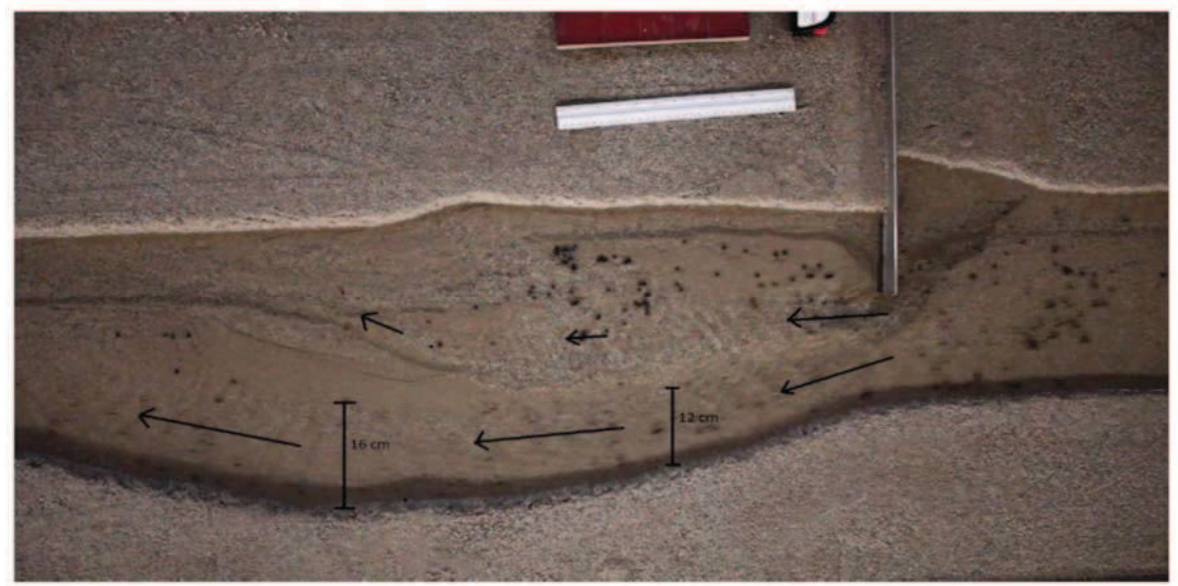

Fig. 4. Measured velocity vectors after 16 hours (final configuration) for the discharge of $0.58 \mathrm{l} / \mathrm{s}$ and $50 \%$ groyne obstruction. 
The numerical simulations of the initial conditions (flat channel bed and parallel banks) show that the bed shear stress produced by the groyne near the opposite bank has its highest values at a certain distance from the narrowed cross-section. This distance, which scales with the channel width, as well as the length of the area presenting the highest bed shear stress, depends on the degree of channel obstruction: longer groynes produce higher bed shear stresses on a larger area located downstream.
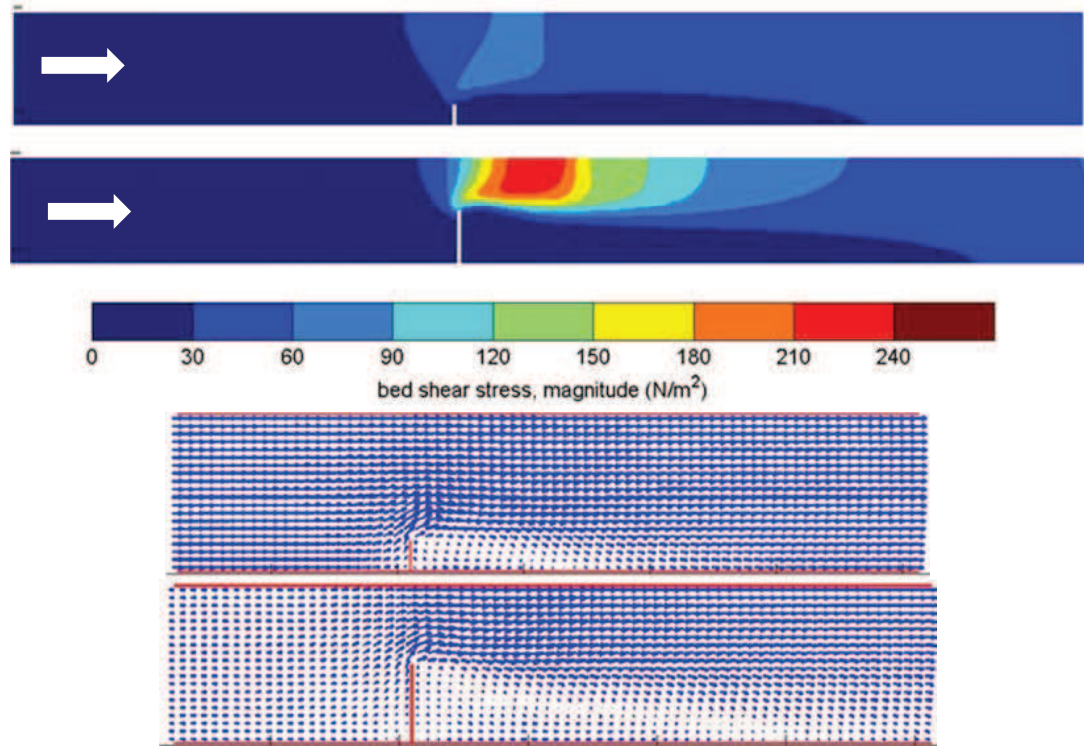

Fig. 5. Computed flow characteristics for a discharge of $347 \mathrm{~m}^{3} / \mathrm{s}$ (upscaled case), corresponding to the experimental discharge of $0.5 \mathrm{l} / \mathrm{s}$. Bed shear stress distribution: A) groyne obstructing $20 \%$ of channel width; B) groyne obstructing $50 \%$ of channel width. Flow velocity vectors (maximum downscaled velocity: $0.45 \mathrm{~m} / \mathrm{s}$ ): C) groyne obstructing $20 \%$ of channel width; D) groyne obstructing $50 \%$ of channel width.

Figure 5 shows the computed distribution of bed shear stress and the flow velocity vectors for the smallest discharge. Backwater effects are more intense with the longest groyne (Figure 5, B and D), resulting in smaller flow velocity in the area upstream of the structure.

\section{Conclusions}

We studied the effects of single groynes on opposite bank erosion and downstream bar formation. We acknowledge that much more research is needed before we are able to draw some robust conclusions and present here only some preliminary results.

In the laboratory we found that opposite bank erosion strongly depends on transverse groyne length and flow characteristics, confirming the findings of [8] and [9], who studied near-groyne morphological developments. The location of maximum bank retreat occurred at a distance from the narrowed cross-section that is equal to 2-3 times the undisturbed channel width, scaling with the flow adaptation length. We found that the development of a forced bar downstream of the groyne is particularly important for opposite bank erosion. This bar influences and is influenced by local channel widening.

The numerical reproduction of the flow field at the initial conditions, with a flat channel bed and parallel banks, allowed analysing the situation before the formation of the forced bar. This helped clarifying the role of the flow constriction caused by the groyne on the processes leading to initial channel widening. Numerical simulations with LES show that the highest bed shear stresses occur downstream of the groyne at a distance that scales with the channel width. The area characterized by maximum bed shear stress is longer if the flow obstruction caused by the groyne is larger. More analysis of the results and more numerical simulations will be carried out in the future. We will study the flow field at the final channel configuration with the bar and will analyse the bed development with a 2D morphodynamic model for several scenarios. 
Part of the work was supported by Netherlands Fellowship Program (NFP), grant CS-SA/MRA/LtB, and by the National Council for Science and Technology of Mexico, CONACyT, grant number 410579.

\section{References}

1. Duró G., A. Crosato, P. Tassi, Adv. Water Resour., 93, 21-38 (2016)

2. Uijttewaal W.S.J., J. Hydraul. Eng., 131, 782-91 (2005).

3. Duan J.G., J. Hydraul. Eng., 135(10), 803-11 (2009).

4. Sukhodolov A.N., J. Hydraul. Res., 52(1), 05-20 (2014).

5. Yossef M.F.M., Uijttewaal W.S.J., Proc. IAHR 30th Congr, Thessaloniki, Greece, 102, 361-368 (2003)

6. Koken M., Constantinescu G., Water Resour. Res., 44(8), 1-19 (2008)

7. McCoy A., Constantinescu G., Weber L.J., J. Hydraul. Eng., 134(2), 157-72 (2008)

8. Garde R.J., Subramanya K., Nambudripad K.D., J. Hydraul. Div., Am. Soc. Civ. Eng., 87(6), 23-38 (1961)

9. Kuhnle R.A., Alonso C.V., Shields F.D., J. Hydraul. Eng.,128(12),1087-1093 (2002)

10. Yossef M.F.M., Klaassen G.J., Proc. RIVER FLOW, 2, 1099-1108 (2002)

11. Struiksma N., Olesen K.W., Flokstra C., De Vriend H.J., J. Hydraul. Res., 23(1), 57-79 (1985)

12. Struiksma, N., A. Crosato, Water Res. Monogr., 12, S. Ikeda and G. Parker eds., 153-180, AGU, Washington, D. C. (1989)

13. Crosato A., E. Mosselman, Water Resour. Res., W03424 (2009)

14. Engelund, F., Hansen, E.. A monograph on sediment transport in alluvial streams. Copenhagen, Danish Technical Press (1967)

15. Jaballah, M., Camenen, B., Pénard, L., Paquier, A., Advances in Water Resources, 81, 103-113 (2015)

16. Le, T.B., Crosato A., Uijttewaal, W.S.J. Adv. in Water Resources, 113, 73-85 (2018) 